\title{
EFFECTS OF SAGITTAL BALANCE DIFFERENCES ON SPONDYLOLISTHESIS
}

\section{EFEITOS DAS DIFERENÇAS DO EQUILÍBRIO SAGITAL NA ESPONDILOLISTESE}

\author{
Zeliha Cosgun ${ }^{1}$,Emine Dagistan ${ }^{1}$, Yasar $_{\text {Dagistan }}^{2}$ \\ 1. Abant Izzet Baysal University, Medical School, Department of Radiology, Bolu, Turkey. \\ 2. Abant Izzet Baysal University, Medical School, Department of Neurosurgery, Bolu, Turkey.
}

\begin{abstract}
Objectives: This study aimed to compare the lumbar lordosis (LL) and spinopelvic parameters of patients with stage 1-2 spondylolisthesis to those of the normal population and demonstrate the importance of these parameters in sagittal balance. Methods: The lumbosacral parameters on the lateral radiographs of a total of 125 patients were retrospectively compared. Lumbosacral parameters including pelvic incidence (PI), pelvic tilt (PT), sacral slope (SS), lumbar lordosis angle (LLA), L5 incidence (L5I), L5 slope (L5S), and sacral table angle (STA) were compared between groups. Results: Comparison of the parameters between groups revealed no sex-based differences ( $p>0.05)$. Conclusions: Abnormal sagittal spinopelvic parameters are commonly examined for their effects on the development of spondylolisthesis and should be used in routine practice. We found that the low SS values in our study, unlike those of other similar studies, may be a compensatory mechanism developed to reduce pain and maintain sagittal balance. Level of Evidence II; retrospective study.
\end{abstract}

Keywords: Spondylolisthesis. Lumbar vertebrae. Lordosis.

\section{RESUMO}

Objetivo: Nosso objetivo é comparar os valores dos parâmetros de $L L$ e espinopélvicos de pacientes com espondilolistese estágios 1 e 2 com a população normal e mostrar a importância desses parâmetros com relação ao balanço sagital. Métodos: As radiografias laterais de um total de 125 pacientes foram avaliadas comparativa e retrospectivamente quanto aos parâmetros lombossacrais. Os parâmetros usados para a avaliação foram IP, InP, IS, ângulo de lordose lombar (ALL), incidência de L5 (In-L5), inclinação L5 (I-L5) e ângulo do platô sacral (APS). Resultados: Os parâmetros lombossacrais IP, InP, IS, ALL, incidência de L5, I-L5 e APS foram comparados entre os grupos controle e espondilolistese. Quando cada parâmetro foi comparado entre homens e mulheres para avaliar o efeito do sexo nos grupos espondilolistese e controle, não houve diferença significativa entre as medidas de ambos os sexos ( $p>0,05)$. Conclusões: Os parâmetros sagitais espinopélvicos anormais são usados comumente no presente por seus efeitos sobre 0 desenvolvimento da espondilolistese e devem fazer parte da prática de rotina. Segundo as avaliações, os baixos valores de IS em nosso estudo, que diferiram de estudos similares, podem ser um mecanismo de compensação desenvolvido pelos pacientes para reduzir a dor e manter o equilíbrio sagital. Nível de Evidência II; Estudo retrospectivo.

Descritores: Espondilolistese. Vértebras lombares. Lordose.

Citation: Cosgun Z, Dagistan E, Dagi tan Y. Effects of sagittal balance differences on spondylolisthesis. Acta Ortop Bras. [online]. 2019;27(2):120-3. Available from URL: http://www.scielo.br/aob.

\section{INTRODUCTION}

The humans are the only living creatures which have lordotic lumbar curvature and lumbar lordosis (LL) is one of the most important parameters to be examined in sagittal balance evaluations due to its variability. ${ }^{1}$ Lumbar lordosis, which varies depending on the shape and the position of the pelvis and the relationship between sacral slope (SS) and pelvic tilt (PT), is thought to be the main mechanical cause of the degenerative diseases of the spine. ${ }^{2}$

The loss of the $\mathrm{LL}$ is an expected finding with the changes in the center of gravity in the aging spine and degenerative disc diseases, which cause spondylolysis, spondylolisthesis, and collapse on discs. With the activation of the other compensatory mechanisms accompanying the loss of lumbar lordosis, the thoracal, thoracolumbar and sacral angles would change. The two basic variables affected in the compensation mechanisms are pelvic tilt (PT) and $\mathrm{SS}$ with the change of $\mathrm{LL}$ in degenerative processes. The term pelvic incidence $(\mathrm{PI})$ is equal to the sum of the two variables, PT and SS. ${ }^{1}$ In the classification of the spinal study group, spondylolisthesis was classified as six types, and spinopelvic parameters which were assessed using the angle of the shifting, PI, SS, PT and sagittal vertical line of $\mathrm{C} 7$ were taken into account when evaluating these types. In this classification, low-grade spondylolisthesis was

All authors declare no potential conflict of interest related to this article.

The study was conducted at Abant Izzet Baysal University, Izzet Baysal Training and Research Hospital, Bolu, Turkey. Correspondence: Yasar Dagistan. Abant Izzet Baysal University, Izzet Baysal Training and Research Hospital, Department of Neurosurgery, 14280, Golkoy, Bolu, Turkey. dagistanyasar@hotmail.com 
classified as meyerding stage $0-2$, shift below $50 \%$; while high-grade spondylolisthesis as meyerding $>3$ and shift $>50 \%$. Today, this classification is commonly used. ${ }^{3}$

Abnormal PI and spinopelvic parameters play essential roles in the development and progression of many spinal diseases including spondylolysis, spondylolisthesis and various other spinal pathologies. ${ }^{4}$ Recent studies showed that pelvis morphology or PI and its orientation significantly affect the sagittal spinal geometry of LL especially, both in healthy and diseased states. ${ }^{5-6}$ Because PT and SS are variable parameters that are affected by the position, pelvic and other sagittal parameters should be assessed withstanding lateral radiographs. ${ }^{1}$

Our aim in this study is to compare the values of the LL and spinopelvic parameters of patients with stage 1-2 spondylolisthesis to the normal population and to show the importance of these parameters regarding sagittal balance.

\section{MATERIALS AND METHODS}

This retrospective study was approved by the ethics committee of Bolu Abant Izzet Baysal University (20187/119). Participants were signed the informed consent form. Among the patients who referred to the neurosurgery outpatient clinic with the complaints of lumbar pain and sciatalgia between 2016 and 2017, seventy-five patients who had no spinal pathology detected with direct radiography (DR) and lumbar magnetic resonance imaging (MRI), and fifty patients with spondylolisthesis were included. The lateral radiographs of a total of 125 patients were evaluated comparatively and retrospectively concerning the lumbosacral parameters.

The exclusion criteria were undergone spinal surgery, lumbar infection, tumor, hip joint disease; the inclusion criteria were the age of 18-70 years and the presence of the lateral radiography which was optimal for the lumbosacral parameter measurement.

A single senior radiologist obtained all lumbosacral parameters on the lateral radiographs obtained on the standing patients via the hospital PACS (imaging) system. The parameters we used for the evaluation were PI, PT, SS, lumbar lordosis angle (LLA), L5 incidence (L5I), L5 slope (L5S) and sacral table angle (STA). PI was the angle between the vertical line passing through the middle point of the superior sacral end plate and the line connecting the femur head axis to this mid point; PT was the angle between the vertical line passing through the femur head axis and the line connecting the femur head axis to the sacral end plate midpoint; SS was the angle between the superior sacral end plate and the horizontal line; LLA was the angle formed by the intersection of the vertical lines from each of the parallel lines which were drawn from the upper-end plates of the first lumbar vertebrae and the sacral vertebra ; L5I was the angle between the line perpendicular to the middle point of the superior L5 end plate and the femur head axis; L5S was the angle between the upper-end plate of the L5 vertebrae and the horizontal line and the STA was the angle between the superior end plates of the sacrum and the line of the posterior sacrum edge (Figure 1). Statistical analysis showed normal distribution in patient and healthy groups and independent sample T-test was performed for the comparison. It was considered significant when the $P$ value was below 0.05. Independent sample T-test was used to assess the gender effect for each parameter, ANOVA test was used to assess the age effect.

\section{RESULTS}

A total of 125 patients, 50 with spondylolisthesis and 75 normal, included in the study ranged between the age of 18-70 years, with a mean age of 49 years. The spondylolisthesis group consisted of 12 males and 38 females and the healthy group consisted of 38 males and 37 females.

Lumbosacral parameters including PI, PT, SS, LLA, L5 incidence, L5S and STA values were compared in healthy and spondylolisthesis groups. Grade 1 listhesis was detected in 43 patients, and grade 2 listhesis was detected in 7 patients in the listhesis group, and when they were compared regarding the lumbosacral parameters, there was no significant difference.

PI, PT, LLA, L5I, L5S values were significantly higher, and STA was significantly lower in the patient group $(p<0,05)$. There was no significant difference in SS values between the two groups (Table1). When each parameter were compared between males and females to assess the gender effect in patient and healthy groups, there was no significant difference between males and females in the measurements. When the healthy and patient groups were divided into three subgroups as 18-39 years, 40-59 years and over 60 years old to evaluate the effect of the age; it was found that there was no significant difference between all age groups in all parameters in both groups.

\section{DISCUSSION}

In our study, there was a significant relationship between the development of spondylolisthesis, and the horizontal and retrovert position of the pelvis due to the increase in PI and PT values and the increased LLA, increased L5I and low STA values as the
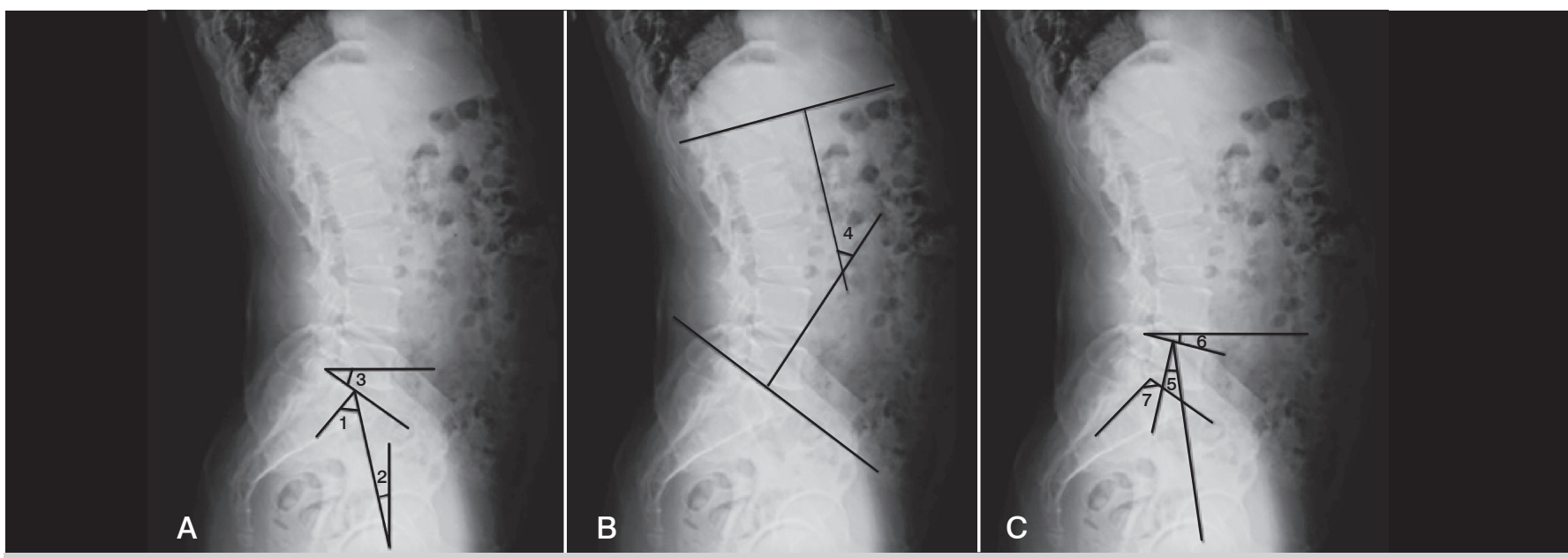

Figure 1. Sagittal lumbosacral parameters (a) 1:PI, 2:PT, 3:SS, (b) 4:LLA, (c) 5:L5I, 6:L5S, 7:STA. 
Table 1. Lumbosacral parameters.

\begin{tabular}{c|c|c|c}
\hline Lumbosacral parameters & $\begin{array}{c}\text { in all parameters } \\
\text { in both groups. } \\
\text { Spondylolisthesis group }\end{array}$ & Normal group & *P value \\
\hline Pelvic incidence & 5512,8 & 4611,2 & $<0,001$ \\
\hline Pelvic tilt & $18,611,5$ & $14,7 \quad 8,01$ & 0,042 \\
\hline Sacral slope & $37,713,32$ & $34,87,9$ & 0,134 \\
\hline Lumbar lordosis angle & $52,913,3$ & $48,211,8$ & 0,042 \\
\hline L5 incidence & $29,811,8$ & $22,29,4$ & 0,001 \\
\hline L5 slope & $22,811,13$ & $17,17,2$ & 0,002 \\
\hline Sacral table angle & $97,45,4$ & $99,924,3$ & $<0,004$ \\
\hline
\end{tabular}

Values are expressed as mean(SD). Significant differences of $p$ values are emphasized in bold, ${ }^{*} p<0.05$ was accepted as statistically significant.

compensatory mechanisms. For this reason, spinopelvic parameters should be included in our routine practice.

In the last decade, the interest in sagittal balance and the researches into parameters related to sagittal balance has been increasing, especially relevant to scoliosis and other spinal deformities. Sagittal lumbosacral parameters have an essential role in the radiological evaluation of lumbar spinal pathologies such as spondylolysis, degenerative lumbar spondylolisthesis, and lumbar disc herniation, and developed the term of pelvic incidence (PI) ${ }^{7,8,9}$

Whitesides et al. found that PI increased from $41.8^{\circ}$ in normal adolescents to $64.5^{\circ}$ in adults with isthmic spondylolisthesis, and there was a statistical correlation between sacral slope and PI values in spondylolisthesis patients. ${ }^{9}$ In the case of decreased PI values, the pelvis forms a vertical position, while the increase of the PI values causes the pelvis to form a horizontal position, andthe force distribution of the secondary gravity on the vertebra varies regarding this. ${ }^{1}$ It is known that the change in this force distribution increases the probability of spondylolysis, and the higher PI values found in the spondylolisthesis group in our study showed parallelism with the literature. Duval-Beaupere et al. also suggested that PI is effective in the formation of isthmic spondylolisthesis, and the larger PI and sacral slope could lead spine to shift. ${ }^{7}$ These findings suggest that $\mathrm{PI}$ is the primary etiologic factor in spondylolisthesis. In the study of Frederickson et al., spondylolysis was considered as pre-spondylolisthesis. ${ }^{10,11}$ In our study, the mean PI value was found to be 55 in the spondylolisthesis group, and it was significantly higher than the normal group (Table1).

PT, another parameter in our study, is a postural parameter that reflects the compensatory ability of the pelvis on the sagittal balance. Labelle et al. showed a correlation between the increase in the severity of spondylolisthesis and PI, SS, PT and lumbar lordosis. 12 Low PT values were associated with pelvic anteversion, and high values were associated with retroversion, and retrograde and horizontal placement of the pelvis was associated with the advanced stage spondylolisthesis. ${ }^{13}$ In our study, the PT values of the patients with grade 1 and two spondylolisthesis were found to be significantly higher than the healthy group.

$\mathrm{PI}$ is equal to the sum of PT and SS. Since PT has a narrow range of angles, usually between 10-15 degrees, it has been found that when pelvic incidence increases, the sacral slope increases more than pelvic tilt. ${ }^{10}$ The relationship between lumber lordosis (LL) and sacral slope (SS) was first noted by Stagnara. ${ }^{14}$ The greater the SS, the greater the LL becomes (the dynamic waist). On the contrary, when the LL gets flattened (the static waist), the SS becomes horizontal. Roussoully et al. reported that high PI values in low-grade developmental spondylolisthesis (Meyerding 0-2) accompany high SS values (> 40 degrees), ${ }_{11}^{11}$ Dissimilar to the literature, we found that there was no change in SS when the PI was increased in our study. This result suggests us that with the unchanging SS as a result of the increase of $\mathrm{PI}, \mathrm{LL}$ and $\mathrm{PT}$, sagittal balance is tried to be maintained in a relatively compensatory manner.

Lumbar lordosis angle is the angle formed by the intersection of the vertical lines from each of the parallel lines which were drawn from the upper-end plates of the L1 vertebra and the S1 vertebra in the lateral lumbar radiography, and it has been reported to be correlated strongly with spinal instability. ${ }^{15,16}$ In the literature, it was reported that as PI values increased, LLA also increased to maintain the sagittal balance, and sacrum formed a horizontal position secondary to this increase. ${ }^{1}$ In our study, PI and LLA values were found significantly higher in the listhesis group in accordance with the literature.

Roussouly et al., who described the term L5I for the first time, stated that $L 5$ I is associated with isthmic lumbar spondylolisthesis. ${ }^{11,12,13}$ In our data, L5I values were significantly higher in the spondylolisthesis group compatible with the other parameters.

In the study conducted by Yukawa et all. thoracic kyphosis and LL showed no significant change between 20 and 60 years of age, but both of them decreased significantly over 70 years of age in Japanese society. PT increases with age, while SS decreases with age.$^{17}$ In many other studies to evaluate sagittal spinopelvic parameters, lumbosacral parameters were shown to remain relatively constant throughout life after skeletal maturation. ${ }^{18} \mathrm{Kim}$ et al. found that there was no significant difference in PI, PT, and SS values between young and old males. ${ }^{19}$ Similarly, in our study, there was no significant difference between lumbosacral parameters in terms of age and gender in both healthy and diseased patients.

Inoue et al. showed a significant decrease in STA values of the patients with spondylolysis and spondylolisthesis. ${ }^{20}$ Whitesides et al. found that individuals with lower STA had a higher probability of developing a pars defect than PI, and that the relation of the STA and the lumbar spondylolysis was stronger. They found that Iow STA values predisposed to spondylolysis by an increase in shear force resulting in producing more mechanical stress in pars interarticularis. ${ }^{9}$ A more vertical sacral table (i.e. a lower STA value) means that there is higher shear stress on the disc and therefore a greater tendency to shift forward in the upright position. In our study, we found that low STA values increased predisposition to spondylolisthesis in accordance with the literature.

\section{CONCLUSION}

Abnormal sagittal spinopelvic parameters; such as the horizontal and retrovert position of the pelvis due to the increase in PI and PT values obtained by the direct radiographs in standing position, increased LL angle, increased L5I and low STA values as of the compensatory mechanism; are the spinopelvic parameters which are commonly used nowadays for their effects on the development of the spondylolisthesis and should take place in the routine practice. It was assessed that low SS values in our study, which were different from other similar studies, may be a compensation mechanism developed by patients to reduce pain and maintain the sagittal balance.

AUTHORS' CONTRIBUTIONS: Each author made significant individual contributions to this manuscript. YD (0000-0002-0767-6359)* performed the surgeries and contributed to the study concept and design; ZD (0000-0003-1996-1568)* analyzed the data and conducted the radiological analysis; ED (0000-0002-0202-8555)* performed the statistical analysis and contributed to the study's intellectual concept. * ORCID (Open Researcher and Contributor ID). 


\section{REFERENCES}

1. Cho Y. Evaluation of Global Sagittal Balance in Koreans Adults. J Korean Neurosurg Soc. 2017;60(5):560-6.

2. Roussouly P, Berthonnaud E, Dimnet J. [Geometrical and mechanical analysis of lumbar lordosis in an asymptomatic population: proposed classification]. Rev Chir Orthop Reparatrice Appar Mot. 2003;89(7):632-9.

3. Mac-Thiong J-M, Duong L, Parent S, Hresko MT, Dimar JR, Weidenbaum M, et al. Reliability of the Spinal Deformity Study Group classification of lumbosacral spondylolisthesis. Spine (Phila Pa 1976). 2012;37(2):E95-102.

4. Mehta VA, Amin A, Omeis I, Gokaslan ZL, Gottfried ON. Implications of spinopelvic alignment for the spine surgeon. Neurosurgery. 2011;76(suppl_1):S42-56.

5. Legaye J, Duval-Beaupere G, Hecquet J, Marty C. Pelvic incidence: a fundamental pelvic parameter for three-dimensional regulation of spinal sagittal curves. Eur Spine J. 1998;7(2):99-103.

6. Roussouly P, Gollogly S, Berthonnaud E, Labelle H, Weidenbaum M. Sagittal alignment of the spine and pelvis in the presence of L5-S1 isthmic lysis and low-grade spondylolisthesis. Spine (Phila Pa 1976). 2006;31(21):2484-90.

7. Duval-Beaupere G, Boisaubert B, Hecquet J, Legaye J, Marty C, Montigny J. Sagittal profile of normal spine changes in spondylolisthesis. In: Harms J., Stürz H. (eds). Severe spondylolisthesis. Heidelberg: Springer; Steinkopff; 2002. p. 21-32

8. Jackson RP, Peterson MD, McManus AC, Hales C. Compensatory spinopelvic balance over the hip axis and better reliability in measuring lordosis to the pelvic radius on standing lateral radiographs of adult volunteers and patients. Spine (Phila Pa 1976). 1998;23(16):1750-67.

9. Whitesides Jr TE, Horton WC, Hutton WC, Hodges L. Spondylolytic spondylolisthesis: a study of pelvic and lumbosacral parameters of possible etiologic effect in two genetically and geographically distinct groups with high occurrence. Spine (Phila Pa 1976). 2005;30(6S):S12-21.

10. Fredrickson BE, Baker D, Mcholick WJ, Yuan HA, Lubicky JP. The Natural-History of Spondylolysis and Spondylolisthesis. J Bone Joint Surg Am. 1984;66a(5):699-707.

11. Roussouly P, editor. Spondylolisthesis, pelvic incidence and spino-pelvic balance: a correlation study. 8th Annual International Meeting of Advanced Spinal Techniques, Paradise Island, Bahamas, 2001; 2001.

12. Labelle H, Roussouly P, Berthonnaud É, Transfeldt E, O'brien M, Chopin D, et al. Spondylolisthesis, pelvic incidence, and spinopelvic balance: a correlation study. Spine (Phila Pa 1976). 2004;29(18):2049-54.

13. Hresko MT, Labelle H, Roussouly P, Berthonnaud E. Classification of high-grade spondylolistheses based on pelvic version and spine balance: possible rationale for reduction. Spine. 2007;32(20):2208-13.

14. Stagnara P, De JM, Dran G, Gonon GP, Costanzo G, Dimnet J, et al. Reciprocal angulation of vertebral bodies in a sagittal plane: approach to references for the evaluation of kyphosis and lordosis. Spine (Phila Pa 1976). 1982;7(4):335-42.

15. Boissiere L, Bourghli A, Vital J-M, Gille O, Obeid I. The lumbar lordosis index: a new ratio to detect spinal malalignment with a therapeutic impact for sagittal balance correction decisions in adult scoliosis surgery. Eur Spine J. 2013;22(6):1339-45.

16. Klotzbuecher CM, Ross PD, Landsman PB, Abbott TA, Berger M. Patients with prior fractures have an increased risk of future fractures: a summary of the literature and statistical synthesis. J Bone and Miner Res. 2000;15(4):721-39.

17. Yukawa Y, Kato F, Suda K, Yamagata M, Ueta T, Yoshida M. Normative data for parameters of sagittal spinal alignment in healthy subjects: an analysis of gender specific differences and changes with aging in 626 asymptomatic individuals. Eur Spine J. 2018;27(2):426-32.

18. Boulay C, Tardieu C, Hecquet J, Benaim C, Mouilleseaux B, Marty C, et al. Sagittal alignment of spine and pelvis regulated by pelvic incidence: standard values and prediction of lordosis. Eur Spine J. 2006;15(4):415-22.

19. Kim YB, Kim YJ, Ahn Y-J, Kang G-B, Yang J-H, Lim H, et al. A comparative analysis of sagittal spinopelvic alignment between young and old men without localized disc degeneration. Eur Spine J. 2014;23(7):1400-6.

20. Inoue H, Ohmori K, Miyasaka K. Radiographic classification of L5 isthmic spondylolisthesis as adolescent or adult vertebral slip. Spine (Phila Pa 1976). 2002;27(8):831-8. 